\title{
Public Health Perspectives of Preeclampsia in Developing Countries: Implication for Health System Strengthening
}

\author{
Kayode O. Osungbade ${ }^{1}$ and Olusimbo K. Ige ${ }^{2}$ \\ ${ }^{1}$ Department of Health Policy and Management, Faculty of Public Health, College of Medicine and University College Hospital, \\ University of Ibadan, P.M.B. 5017 General Post Office, Ibadan, Nigeria \\ ${ }^{2}$ Department of Community Medicine, University College Hospital, P.M.B. 5116, Ibadan, Nigeria
}

Correspondence should be addressed to Kayode O. Osungbade, koosungbade@yahoo.com

Received 13 October 2010; Revised 20 December 2010; Accepted 19 January 2011

Academic Editor: Sean Blackwell

Copyright ( $) 2011$ K. O. Osungbade and O. K. Ige. This is an open access article distributed under the Creative Commons Attribution License, which permits unrestricted use, distribution, and reproduction in any medium, provided the original work is properly cited.

\begin{abstract}
Objectives. Review of public health perspectives of preeclampsia in developing countries and implications for health system strengthening. Methods. Literature from Pubmed (MEDLINE), AJOL, Google Scholar, and Cochrane database were reviewed. Results. The prevalence of preeclampsia in developing countries ranges from $1.8 \%$ to $16.7 \%$. Many challenges exist in the prediction, prevention, and management of preeclampsia. Promising prophylactic measures like low-dose aspirin and calcium supplementation need further evidence before recommendation for use in developing countries. Treatment remains prenatal care, timely diagnosis, proper management, and timely delivery. Prevailing household, community, and health system factors limiting effective control of preeclampsia in these countries were identified, and strategies to strengthen health systems were highlighted. Conclusion. Overcoming the prevailing challenges in the control of preeclampsia in developing countries hinges on the ability of health care systems to identify and manage women at high risk.
\end{abstract}

\section{Introduction}

Preeclampsia is a pregnancy-related hypertensive disorder occurring usually after 20 weeks of gestation. If left untreated, it progresses to eclampsia [1]. Preeclampsia and eclampsia are not distinct disorders but the manifestation of the spectrum of clinical symptoms of the same condition. The mildest disorder in this continuum is pregnancy-induced hypertension. In preeclampsia, hypertension and proteinuria are present, and when convulsions occur in addition to these signs, the condition is referred to as eclampsia [2].

Preeclampsia has remained a significant public health threat in both developed and developing countries contributing to maternal and perinatal morbidity and mortality globally [3-6]. However, the impact of the disease is felt more severely in developing countries $[7,8]$, where, unlike other more prevalent causes of maternal mortality (such as haemorrhage and sepsis), medical interventions may be ineffective due to late presentation of cases [9-11]. The problem is confounded by the continued mystery of the aetiology and the unpredictable nature of the disease [12]. Thus, the aim of this paper is to highlight the challenges militating against effective control of preeclampsia in developing countries and suggest measures which could be used to address them within the local context.

\section{Methods}

Literature providing evidence on the diagnosis, prevention, treatment, and overcoming challenges to the control of preeclampsia published between 2000 and 2010 were reviewed. Search terms included "preeclampsia", "eclampsia", "developing countries", and "control". These literatures were accessed from Pubmed (MEDLINE), AJOL, Google Scholar, and Cochrane Database of Systematic Reviews. Searches were also supplemented with recommendations from outside experts and reviews of bibliographies of other relevant articles and systematic reviews. 


\section{Results}

3.1. Burden of Preeclampsia. Worldwide, the incidence of preeclampsia ranges between $2 \%$ and $10 \%$ of pregnancies. The incidence of preeclampsia, the precursor to eclampsia, varies greatly worldwide. WHO estimates the incidence of preeclampsia to be seven times higher in developing countries (2.8\% of live births) than in developed countries $(0.4 \%)$ [13]. The incidence of eclampsia in the developed countries of North America and Europe is similar and estimated to be about 5-7 cases per 10,000 deliveries. On the other hand, incidence of eclampsia in developing nations varies widely, ranging from 1 case per 100 pregnancies to 1 case per 1700 pregnancies $[2,14]$. Rates from African countries such as South Africa, Egypt, Tanzania, and Ethiopia vary from $1.8 \%$ to $7.1 \%$ [15-18]. In Nigeria, prevalence ranges between $2 \%$ to $16.7 \%$ [19-21].

\subsection{Public Health Perspectives of Preeclampsia}

3.2.1. Challenges in Detection and Prevention of Preeclampsia. Prevention of any disease process requires the availability of methods for prediction of those at high risk for the disorder. Although numerous clinical and biochemical tests have been proposed for prediction or early detection of preeclampsia, most remain unrealistic for general use in most developing countries. At present, there is not a single reliable and cost-effective screening test for preeclampsia which can be recommended for use in most developing countries [22]. Although some studies on uterine artery Doppler studies and first-trimester maternal serum markers for early detection of preeclampsia have shown promise [23-25]. There is not enough evidence to suggest their routine use in clinical practice, more so in resource poor settings [26].

In terms of prophylaxis, aspirin therapy has been shown to be beneficial in decreasing the occurrence of preeclampsia in specific populations, for example, those with abnormal second trimester uterine Doppler flow [27-30]. However, to recommend its widespread use in all patients is not judicious or evidence based. In the same vein, even though the Cochrane review has stated some benefit in calcium supplementation, particularly for those at greatest risk and those with low baseline calcium intake [31,32], the problem of selecting appropriate patients to be started on the therapy can be burdensome from a public health perspective. Similarly, findings of earlier studies which had indicated the benefits of vitamin supplementation [33-39] have been refuted by a recent study by the WHO particularly for vitamins $\mathrm{C}$ and $\mathrm{E}[40]$.

3.2.2. Challenges in the Management of Preeclampsia. It is evident that to tackle preeclampsia effectively in any population, functional health systems are imperative and so is access to health care. However, in the vast majority of developing countries particularly in Africa, health care access is limited due to a number of factors resulting in three levels of delay.
Delay in the Decision to Seek Care. Delayed responses at the household level to obstetric emergencies often arise as a result of inadequate information on when to seek help and sometimes on where to seek help [41-43]. This is worsened by lack of decision-making power, poverty, and the rising cost of health care $[44,45]$. The consideration of user fees and the resultant catastrophic expenditure often result in fatal delays in care seeking [46]. Some sociodemographic (e.g., level of education and marital status) and cultural underpinnings of maternal health-seeking behaviour have also been documented [47].

Delay in Reaching the Health Facility. Lack of access to quality care has been said to be the main obstacle to reducing maternal mortality in low-income countries [46]. These are due to the location, distance, and lack of transport to health facilities. In Nigeria, for example, up to $50 \%$ of rural women live more than $5 \mathrm{~km}$ from the nearest hospital, and many have no way to get to health facilities except by walking-even when in labour [48]. The inequitable distribution of health facilities which is in favour of urban communities is also contributory [21]. Furthermore, the referral delays arising from the trajectory of visits to other orthodox and alternative medical practitioners have been documented to account for $46.4 \%$ of all cases of eclampsia $[49,50]$.

Delays in Health Service Provision. Delays which arise in health facilities have also been shown to prevent women from receiving the care they need before, during, and after childbirth. For instance, in many countries where the health insurance scheme is still in the teething stage, getting care in emergencies may be impossible for the poor or insured [51]. The attitudes of health service providers and perceived poor quality of care are also identified barriers $[4,52]$. This is made worse by the lack of trained personnel and lack of equipment and supplies [45]. For instance, even though the efficacy of magnesium sulphate has been documented by several researchers [21,53], studies have shown that magnesium sulphate was not routinely administered $[41,54]$, and use is often limited to teaching hospitals [55]. Lack of availability of the drug and appropriate health personnel required for its administration as well as cost were the frequently raised obstacles [56].

3.2.3. Health Policies. At macro- and microhealth system levels, there are deficient policy guidelines and implementation. This has been blamed on poor data for decision making [56]. For example, reliable statistics about women dying due to eclampsia are difficult to obtain because of the poor quality of vital statistics registration systems and hospital records in many developing countries [57]. In addition, a sizable number of deliveries take place at home, and thus, there are no records at all for these births or their sequelae [56]. In addition, health policy development is usually not evidence based. This is because policy makers are often poorly informed of, and insufficiently involved in the use of research in policy development [58]. 


\subsection{Recommendations}

3.3.1. Risk Assessment and Clinical Management. The WHO focused antenatal care strategy recommends screening for preeclampsia during the third antenatal visit at 32 weeks [59]. In developing countries, strategies for risk assessment should still be based on obstetric and medical history and clinical examination of women. Pregnant women should be assessed at their first antenatal clinic for risk factors of preeclampsia such as young age, nulliparity, first pregnancy after age of 35 years, obesity prior to the current pregnancy, multiple gestation, prior history of preeclampsia, diabetes mellitus, and hypertension [1, 60-62]. It is, however, important to note that the presence of these factors is not a surety to developing preeclampsia. It has been shown that screening for preeclampsia using maternal history was accurate in only $45.3 \%$ of cases [63].

Routine screening for preeclampsia based on measurement of blood pressure among all pregnant women should be practised as recommended by the World Health Organization $[64,65]$. Where resources are available it is best to measure blood pressure using a mercury sphygmomanometer [66]. Urinalysis for protein should also be routinely done at every antenatal visit for pregnant women in developing countries as a complement to routine blood pressure measurement. The diagnostic criteria for preeclampsia developed by the National Blood Pressure Education Program Working Group which are still traditionally used in clinical practice are systolic blood pressure of $140 \mathrm{~mm} \mathrm{Hg}$ or higher or a diastolic blood pressure of $90 \mathrm{~mm} \mathrm{Hg}$ or higher on at least two occasions at least 4-6 hours apart occurring after 20 weeks of gestation in a woman whose blood pressure had previously been normal. In addition to this, the presence of proteinuria with excretion of $0.3 \mathrm{~g}$ or more of protein in a 24 hour urine specimen or $1+$ or greater on two random urine samples collected four or more hours apart $[67,68]$.

Once recognised, depending on the severity, options of care include continued foetal and maternal evaluation, antihypertensive therapy, and timely delivery (the only definitive cure). There is significant evidence which supports the use of magnesium sulphate to prevent seizures in women with severe preeclampsia and eclampsia [1, 67, 69]. Magnesium sulphate has been compared with diazepam [70], phenytoin [71], and lytic cocktail [72] in randomized trials and results revealed that it produced a greater reduction in the risk of maternal death and recurrence of convulsions than other agents [73].

Furthermore, a continuum of care must be ensured. For women to benefit from the existing cost-effective interventions, they must have antenatal care in pregnancy, skilled care during delivery and postnatal care [74]. While antenatal care and skilled delivery could prevent seizures, postnatal visits are important to assess the recovery of the woman and to discuss what might happen in the future.

3.3.2. Society and Community Interventions. Social factors have been recognised as influencing up to $27 \%$ of maternal deaths [75]. So, raising awareness of the need for women to reach emergency care without delay if complications arise during delivery is particularly critical. This is to ensure quick and effective medical intervention and to increase the chance of therapeutic success $[1,44]$. Since many women deliver alone or with a relative [48], community members must also be trained to recognize danger signs and develop plans for emergencies, including transport to hospitals or health centre. Prompt health seeking behaviour is essential because reduction of the risk of death becomes more difficult when complications have developed [44].

3.3.3. Health System Strengthening. The majority of intrapartum maternal deaths have been shown to occur in poorly performing health systems [76]. The evidence provided by some developing countries who have shown remarkable reduction in maternal mortality $[75,77,78]$ shows that maternal safety must be made a priority health issue by the government and health workers. An increased focus on quality and accountability is also needed to secure the trust of consumers [79]. Political commitment to mobilize necessary resources to the health sector to improve the quality of emergency obstetric service must be shown by ensuring the availability of trained personnel, drugs, and equipment at every level of care. Referral services to emergency obstetric care must be prompt and affordable to limit delays when skills or facilities are lacking [80]. Improvements in service delivery can be achieved through the use of case management protocols for obstetric emergencies at each level of care and by monitoring standards of practice. Magnesium sulphate should be part of every developing country's list of essential drugs and national protocols on magnesium sulphate as the preferred treatment for preeclampsia and eclampsia should be developed and/or reinforced. To improve maternal health, barriers to accessing health services must be identified and addressed at all levels, with intensified efforts at community mobilization and engagement [81]. The use of data to improve quality of care is also important especially improving reporting systems and record-keeping practices to estimate disease burden to aid service planning and delivery [78]. Maternal death audits would aid the understanding of the pathways to survival and death and help in local efforts at improvement. It would also aid in identifying substandard care and avoidable factors in eclampsia-related maternal deaths $[56,82]$.

\section{Conclusions}

With the target of the Millennium Development Goals in sight, preeclampsia/eclampsia needs to be identified as a priority area in reducing maternal mortality in developing countries. Since the mainstay of control remains health care based strategies, national governments and supporting agencies should channel efforts at strengthening the public health systems and improving access to trained health care providers. Further research is needed to understand the causes and the best preventive strategies for preeclampsia specific to geographic areas. However, based on current data, better access to appropriate obstetric care, particularly 
during labour and delivery and better screening and treatment of identified cases should reduce preeclampsia rates in developing countries.

\section{References}

[1] "Medicine for Africa - Medical Information Service. preeclampsia/ eclampsia," 2008, http://www.medicinemd.com/.

[2] A. K. Shah, "Preeclampsia and Eclampsia," 2009, http:// emedicine.medscape.com/article/1184270-overview.

[3] World Health Organization, "Global Program to Conquer Preeclampsia/Eclampsia,” 2002.

[4] C. Dolea and C. AbouZahr, "Global burden of hypertensive disorders of pregnancy in the year 2000," in Global Burden of Diseases, World Health Organization, 2000.

[5] A. Shah, B. Fawole, J. M. M'Imunya et al., "Cesarean delivery outcomes from the WHO global survey on maternal and perinatal health in Africa," International Journal of Gynecology and Obstetrics, vol. 107, no. 3, pp. 191-197, 2009.

[6] E. M. McClure, S. Saleem, O. Pasha, and R. L. Goldenberg, "Stillbirth in developing countries: a review of causes, risk factors and prevention strategies," Journal of Maternal-Fetal and Neonatal Medicine, vol. 22, no. 3, pp. 183-190, 2009.

[7] G. Igberase and P. Ebeigbe, "Eclampsia: ten-years of experience in a rural tertiary hospital in the Niger delta, Nigeria," Journal of Obstetrics and Gynaecology, vol. 26, no. 5, pp. 414417, 2006.

[8] Y. M. Adamu, H. M. Salihu, N. Sathiakumar, and G. R. Alexander, "Maternal mortality in Northern Nigeria: a populationbased study," European Journal of Obstetrics Gynecology and Reproductive Biology, vol. 109, no. 2, pp. 153-159, 2003.

[9] J. I. Ikechebelu and C. C. Okoli, "Review of eclampsia at the Nnamdi Azikiwe University teaching hospital, Nnewi (January 1996-December 2000)," Journal of Obstetrics and Gynaecology, vol. 22, no. 3, pp. 287-290, 2002.

[10] S. O. Onuh and A. O. Aisien, "Maternal and fetal outcome in eclamptic patients in Benin City, Nigeria," Journal of Obstetrics and Gynaecology, vol. 24, no. 7, pp. 765-768, 2004.

[11] J. U. E. Onakewhor and E. P. Gharoro, "Changing trends in maternal mortality in a developing country," Nigerian Journal of Clinical Practice, vol. 11, no. 2, pp. 111-120, 2008.

[12] L. Duley, "Pre-eclampsia and the hypertensive disorders of pregnancy," British Medical Bulletin, vol. 67, pp. 161-176, 2003.

[13] WHO, Make every mother and child count, in The world health report 2005, World Health Organization, Geneva, Switzerland, 2005.

[14] WHO, Coverage of Maternity Care: A Listing of Available Information, World Health Organization, Geneva, Switzerland, 2004.

[15] K. G. Kimbally, H. Barassoumbi, S. F. Buambo et al., "Arterial hypertension: epidemiological aspects and risk factors on pregnant and delivered woman," Dakar Médical, vol. 52, no. 2, pp. 148-152, 2007.

[16] H. M. Mahaba, N. A. Ismail, S. I. El Damaty, and H. A. Kamel, "Pre-eclampsia: epidemiology and outcome of 995 cases," The Journal of the Egyptian Public Health Association, vol. 76, no. 5-6, pp. 357-368, 2001.

[17] M. Thiam, M. Goumbala, S. B. Gning, P. D. Fall, C. Cellier, and J. L. Perret, "Maternel and fetal prognosis of hypertension and pregnancy in Africa (Senegal)," Journal de Gynecologie Obstetrique et Biologie de la Reproduction, vol. 32, no. 1, pp. 35-38, 2003.
[18] S. Teklu and A. Gaym, "Prevalence and clinical correlates of the hypertensive disorders of pregnancy at Tikur Anbessa Hospital, Addis Ababa, Ethiopia," Ethiopian Medical Journal, vol. 44, no. 1, pp. 17-26, 2006.

[19] A. Omole-Ohonsi and A. O. Ashimi, "Pre-eclampsia: a study of risk factors," Nigerian Medical Practitioner, vol. 53, no. 6, pp. 99-102, 2008.

[20] F. E. Olopade and T. O. Lawoyin, "Maternal mortality in a Nigerian Maternity Hospital," African Journal Biomedical Research, vol. 11, no. 3, pp. 267-273, 2008.

[21] Population Council Nigeria, "Administering Magnesium Sulfate to Treat Severe Pre-eclampsia and Eclampsia," 2009, http://www.popcouncil.org/scripts/tellafriend.asp.

[22] L. K. Wagner, "Diagnosis and management of preeclampsia," American Family Physician, vol. 70, no. 12, pp. 2317-2324, 2004.

[23] S. Kharb, "Serum markers in pre-eclampsia," Biomarkers, vol. 14, no. 6, pp. 395-400, 2009.

[24] F. Audibert, I. Boucoiran, N. An et al., "Screening for preeclampsia using first-trimester serum markers and uterine artery Doppler in nulliparous women," American Journal of Obstetrics and Gynecology, vol. 203, no. 4, pp. 383.e1-383.e8, 2010.

[25] Yale University, "Simple test can help predict and diagnose preeclampsia," ScienceDaily, February 5, 2010.

[26] A. T. Papageorghiou and S. Campbell, "First trimester screening for preeclampsia," Current Opinion in Obstetrics and Gynecology, vol. 18, no. 6, pp. 594-600, 2006.

[27] K. Louden and M. Kilby, "Low-dose aspirin: the rationale for preventing pre-eclampsia and intra-uterine growth retardation: a role after CLASP?" in Recent Advances in Obstetrics and Gynaecology, No 19, J. Bonnar, Ed., Churchill Livingstone, Edinburgh, UK, 1995.

[28] E. Bujold, S. Roberge, Y. Lacasse et al., "Prevention of preeclampsia and intrauterine growth restriction with aspirin started in early pregnancy: a meta-analysis," Obstetrics and Gynecology, vol. 116, no. 2, pp. 402-414, 2010.

[29] L. Duley, D. Henderson-Smart, M. Knight, and J. King, "Antiplatelet drugs for prevention of pre-eclampsia and its consequences: systematic review," British Medical Journal, vol. 322, no. 7282, pp. 329-333, 2001.

[30] M. Knight, L. Duley, D. J. Henderson-Smart, and J. F. King, "Antiplatelet agents for preventing and treating preeclampsia," Cochrane Database of Systematic Reviews, no. 2, Article ID CD000492, 2000.

[31] A. N. Atallah, G. J. Hofmeyr, and L. Duley, "Calcium supplementation during pregnancy for preventing hypertensive disorders and related problems," Cochrane Database of Systematic Reviews, no. 1, Article ID CD001059, 2002.

[32] G. J. Hofmeyr, T. A. Lawrie, A. N. Atallah, and L. Duley, "Calcium supplementation during pregnancy for preventing hypertensive disorders and related problems," Cochrane Database of Systematic Reviews, vol. 8, Article ID CD001059, 2010.

[33] L. M. Bodnar, J. M. Catov, H. N. Simhan, M. F. Holick, R. W. Powers, and J. M. Roberts, "Maternal vitamin D deficiency increases the risk of preeclampsia," Journal of Clinical Endocrinology and Metabolism, vol. 92, no. 9, pp. 3517-3522, 2007.

[34] R. K. Marya, S. Rathee, and M. Manrow, "Effect of calcium and vitamin D supplementation on toxaemia of pregnancy," Gynecologic and Obstetric Investigation, vol. 24, no. 1, pp. 38 42, 1987. 
[35] S. F. Olsen and N. J. Secher, "A possible preventive effect of low-dose fish oil on early delivery and pre-eclampsia: Indications from a 50-year-old controlled trial," British Journal of Nutrition, vol. 64, no. 3, pp. 599-609, 1990.

[36] L. M. Bodnar, G. Tang, R. B. Ness, G. Harger, and J. M. Roberts, "Periconceptional multivitamin use reduces the risk of preeclampsia," American Journal of Epidemiology, vol. 164, no. 5, pp. 470-477, 2006.

[37] J. M. Roberts, J. L. Balk, L. M. Bodnar, J. M. Belizán, E. Bergel, and A. Martinez, "Nutrient involvement in preeclampsia," Journal of Nutrition, vol. 133, no. 5, pp. 1684S-1692S, 2003.

[38] S. W. Wen, XI. K. Chen, M. Rodger et al., "Folic acid supplementation in early second trimester and the risk of preeclampsia," American Journal of Obstetrics and Gynecology, vol. 198, no. 1, pp. 45.e1-45.e7, 2008.

[39] L. C. Chappell, P. T. Seed, A. L. Briley et al., "Effect of antioxidants on the occurrence of pre-eclampsia in women at increased risk: a randomised trial," Lancet, vol. 354, no. 9181, pp. 810-816, 1999.

[40] J. Villar, M. Purwar, M. Merialdi et al., "World Health Organisation multicentre randomised trial of supplementation with vitamins $\mathrm{C}$ and e among pregnant women at high risk for pre-eclampsia in populations of low nutritional status from developing countries," BJOG, vol. 116, no. 6, pp. 780-788, 2009.

[41] O. Akinola et al., "Improving the clinical outcome in cases of eclampsia: the experience at Lagos State University Teaching Hospital, Ikeja," The Internet Journal of Third World Medicine, vol. 6, no. 2, 2008.

[42] T. Wasim, M. Gull, and S. Siddiq, "Eclampsia, a major cause of maternal \& perinatal morbidity and mortality," The Professional, vol. 11, no. 3, pp. 1-6, 2004.

[43] J. Brunson, "Confronting maternal mortality, controlling birth in Nepal: the gendered politics of receiving biomedical care at birth," Social Science and Medicine, vol. 71, no. 10, pp. 1719-1727, 2010.

[44] M. R. Begum, A. Begum, E. Quadir, S. Akhter, and L. Shamsuddin, "Eclampsia: still a problem in Bangladesh," MedGenMed, vol. 6, no. 4, pp. 52-54, 2004.

[45] H. Bracken, "Barriers to magnesium sulfate use for preeclampsia: a case study from India," in Proceedings of the Global Maternal Health Conference, New Delhi, India, 2010.

[46] F. Richard, S. Witter, and V. De Brouwere, "Innovative approaches to reducing financial barriers to obstetric care in low-income countries," American Journal of Public Health, vol. 100, no. 10, pp. 1845-1852, 2010.

[47] B. O. Olusanya, O. P. Alakija, and V. A. Inem, "Non-uptake of facility-based maternity services in an inner-city community in Lagos, Nigeria: an observational study," Journal of Biosocial Science, vol. 42, no. 3, pp. 341-358, 2010.

[48] NPC, Nigeria Demographic and Health Survey 2008, National Population Commission Federal Republic of Nigeria, Abuja, Nigeria, 2009.

[49] H. E. Onah, J. M. Okaro, U. Umeh, and C. O. Chigbu, "Maternal mortality in health institutions with emergency obstetric care facilities in Enugu State, Nigeria," Journal of Obstetrics and Gynaecology, vol. 25, no. 6, pp. 569-574, 2005.

[50] O. K. Ige and C. C. Nwachukwu, "Health care seeking behaviour among market traders in Ibarapa Central Local Government, Nigeria," The Internet Journal of Health, vol. 9, no. 2, 2009.

[51] O. Onwujekwe and B. Uzochukwu, "Socio-economic and geographic differentials in costs and payment strategies for primary healthcare services in Southeast Nigeria," Health Policy, vol. 71, no. 3, pp. 383-397, 2005.

[52] O. K. Ige and C.C. Nwachukwu, "Areas of dissatisfaction with primary health care services in government owned health facilities in a semi urban community in Nigeria," Journal of Rural and Tropical Public Health, vol. 9, pp. 19-23, 2010.

[53] J. Tukur and Z. Muhammad, "Management of eclampsia at AKTH: before and after magnesium sulphate," Nigerian Journal of Medicine, vol. 19, no. 1, pp. 104-107, 2010.

[54] C. Diaz, "Magnesium sulfate use for the treatment of severe preeclampsia and eclampsia in Mexico," in Proceedings of the Global Maternal Health Conference, New Delhi, India, 2010.

[55] W. Getaneh and S. Kumbi, "Use of magnesium sulfate in preeclampsia and eclampsia in teaching hospitals in Addis Ababa: a practice audit," Ethiopian Medical Journal, vol. 48, no. 2, pp. 157-164, 2010.

[56] G. Woelk, K. Daniels, J. Cliff et al., "Translating research into policy: lessons learned from eclampsia treatment and malaria control in three southern African countries," Health Research Policy and Systems, vol. 7, article no. 31, 2009.

[57] P. Tugwell, V. Robinson, and E. Morris, "Mapping global health inequlities: challenges and opportunities," in Center for Global, International and Regional Studies, University of California, Santa Cruz, Calif, USA, 2007.

[58] M. Aaserud, S. Lewin, S. Innvaer et al., "Translating research into policy and practice in developing countries: a case study of magnesium sulphate for pre-eclampsia," BMC Health Services Research, vol. 5, article no. 68, 2005.

[59] WHO, Antenatal Care, in Report of a Technical Working Group, World Health Organisation, Geneva, Switzerland, 1994.

[60] A. Conde-Agudelo and J. M. Belizán, "Risk factors for preeclampsia in a large cohort of Latin American and Caribbean women," British Journal of Obstetrics and Gynaecology, vol. 107, no. 1, pp. 75-83, 2000.

[61] E. B. Magnussen, L. J. Vatten, T. I. Lund-Nilsen, K. Å. Salvesen, G. D. Smith, and P. R. Romundstad, "Prepregnancy cardiovascular risk factors as predictors of pre-eclampsia: population based cohort study," British Medical Journal, vol. 335, no. 7627, pp. 978-981, 2007.

[62] C. S. Packer, "Biochemical markers and physiological parameters as indices for identifying patients at risk of developing pre-eclampsia," Journal of Hypertension, vol. 23, no. 1, pp. 4546, 2005.

[63] A. T. Papageorghiou, C. K. H. Yu, I. E. Erasmus, H. S. Cuckle, and K. H. Nicolaides, "Assessment of risk for the development of pre-eclampsia by maternal characteristics and uterine artery Doppler," BJOG, vol. 112, no. 6, pp. 703-709, 2005.

[64] WHO, Antenatal Care in Developing Countries: Promises, Achievements and Missed Opportunities, World Health Organization, Geneva, Switzerland, 2003.

[65] R. C. Hermida, D. E. Ayala, and M. Iglesias, "Circadian rhythm of blood pressure challenges office values as the "gold standard" in the diagnosis of gestational hypertension," Chronobiology International, vol. 20, no. 1, pp. 135-156, 2003.

[66] "Could oedema and proteinuria in pregnancy be used to screen for high risk?: The WHO International Collaborative Study of Hypertensive Disorders of Pregnancy," Paediatric and Perinatal Epidemiology, vol. 2, no. 1, pp. 25-42, 1988.

[67] B. M. Schroeder, "ACOG practice bulletin on diagnosing and managing preeclampsia and eclampsia," American Family Physician, vol. 66, no. 2, pp. 330-331, 2002.

[68] L. Duley, "Pre-eclampsia, eclampsia, and hypertension," Clinical Evidence, vol. 2008, p. 1402, 2008. 
[69] L. Duley, "Do women with pre-eclampsia, and their babies, benefit from magnesium sulphate? The Magpie Trial: a randomised placebo-controlled trial," Lancet, vol. 359, no. 9321, pp. 1877-1890, 2002.

[70] L. Duley and D. Henderson-Smart, "Magnesium sulphate versus diazepam for eclampsia," Cochrane Database of Systematic Reviews, no. 4, Article ID CD000127, 2003.

[71] L. Duley and D. Henderson-Smart, "Magnesium sulphate versus phenytoin for eclampsia," Cochrane Database of Systematic Reviews, no. 4, Article ID CD000128, 2003.

[72] L. Duley and A. M. Gulmezoglu, "Magnesium sulphate versus lytic cocktail for eclampsia," Cochrane Database of Systematic Reviews, no. 3, Article ID CD002960, 2000.

[73] M. Aaserud, S. Lewin, S. Innvaer et al., "Translating research into policy and practice in developing countries: a case study of magnesium sulphate for pre-eclampsia," BMC Health Services Research, vol. 5, article no. 68, 2005.

[74] B. Chigbu, S. Onwere, C. I. Kamanu, C. Aluka, O. Okoro, and E. Adibe, "Pregnancy outcome in booked and unbooked mothers in South Eastern Nigeria," East African Medical Journal, vol. 86, no. 6, pp. 267-271, 2009.

[75] L. Qiu, J. Lin, Y. Ma et al., "Improving the maternal mortality ratio in Zhejiang Province, China, 1988-2008," Midwifery, vol. 26, no. 5, pp. 544-548, 2010.

[76] J. E. Lawn, M. Kinney, A. C. Lee et al., "Reducing intrapartumrelated deaths and disability: can the health system deliver?" International Journal of Gynaecology and Obstetrics, vol. 107, pp. S123-S140, 2009.

[77] S. S. Lim, L. Dandona, J. A. Hoisington, S. L. James, M. C. Hogan, and E. Gakidou, "India's Janani Suraksha Yojana, a conditional cash transfer programme to increase births in health facilities: an impact evaluation," The Lancet, vol. 375, no. 9730, pp. 2009-2023, 2010.

[78] N. Prata, P. Passano, A. Sreenivas, and C. E. Gerdts, "Maternal mortality in developing countries: challenges in scaling-up priority interventions," Women's Health, vol. 6, no. 2, pp. 311$327,2010$.

[79] $\varnothing$. E. Olsen, "The impact of global health initiatives on trust in health care provision under extreme resource scarcity: presenting an agenda for debate from a case study of emergency obstetric care in Northern Tanzania," Health Research Policy and Systems, vol. 8, article no. 14, 2010.

[80] K. T. Ijadunola, M. Y. Ijadunola, O. A. Esimai, and T. C. Abiona, "New paradigm old thinking: The case for emergency obstetric care in the prevention of maternal mortality in Nigeria," BMC Women's Health, vol. 10, article no. 6, 2010.

[81] A. C. Lee, J. E. Lawn, S. Cousens et al., "Linking families and facilities for care at birth: what works to avert intrapartumrelated deaths?" International Journal of Gynaecology and Obstetrics, vol. 107, pp. S65-S86, 2009.

[82] B. L. Sorensen, P. Elsass, B. B. Nielsen, S. Massawe, J. Nyakina, and V. Rasch, "Substandard emergency obstetric care- a confidential enquiry into maternal deaths at a regional hospital in Tanzania," Tropical Medicine and International Health, vol. 15, no. 8, pp. 894-900, 2010. 


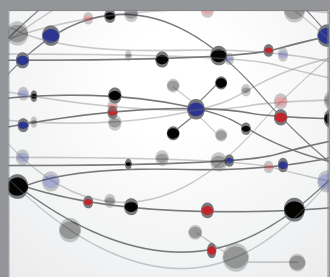

The Scientific World Journal
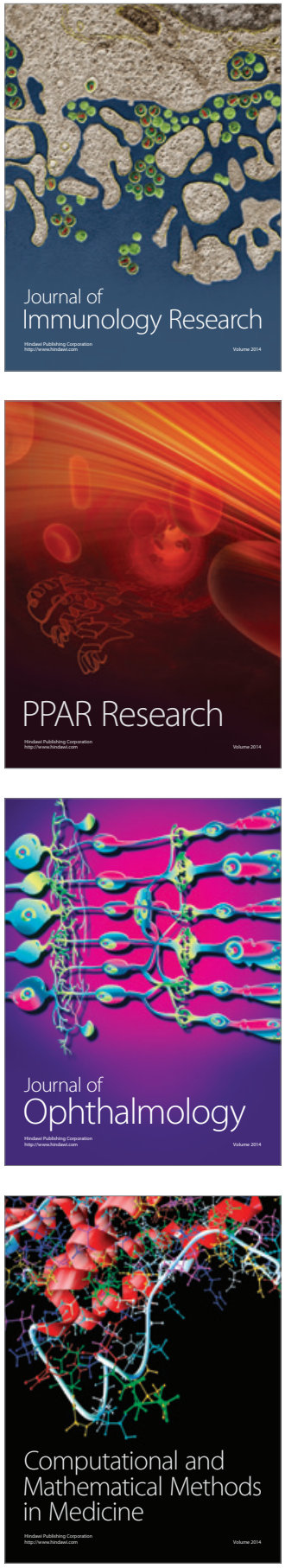

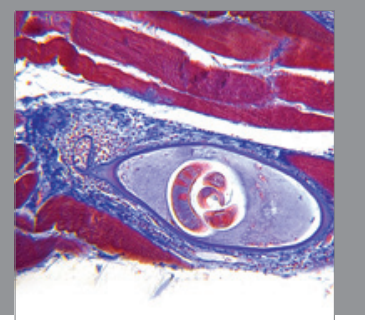

Gastroenterology

Research and Practice
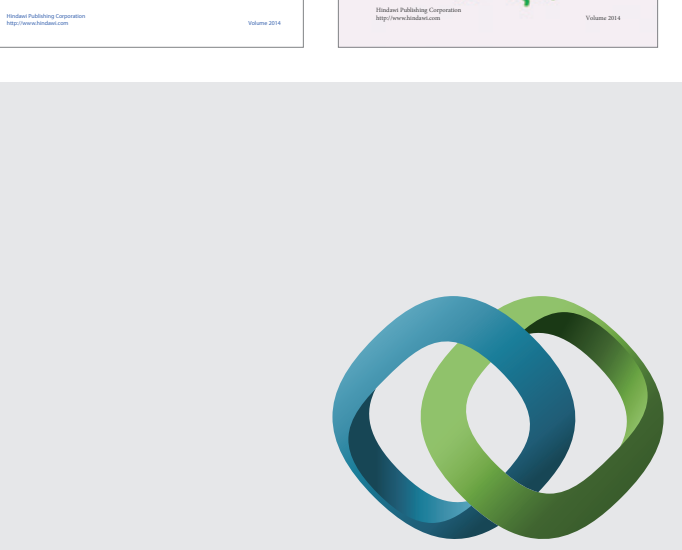

\section{Hindawi}

Submit your manuscripts at

http://www.hindawi.com
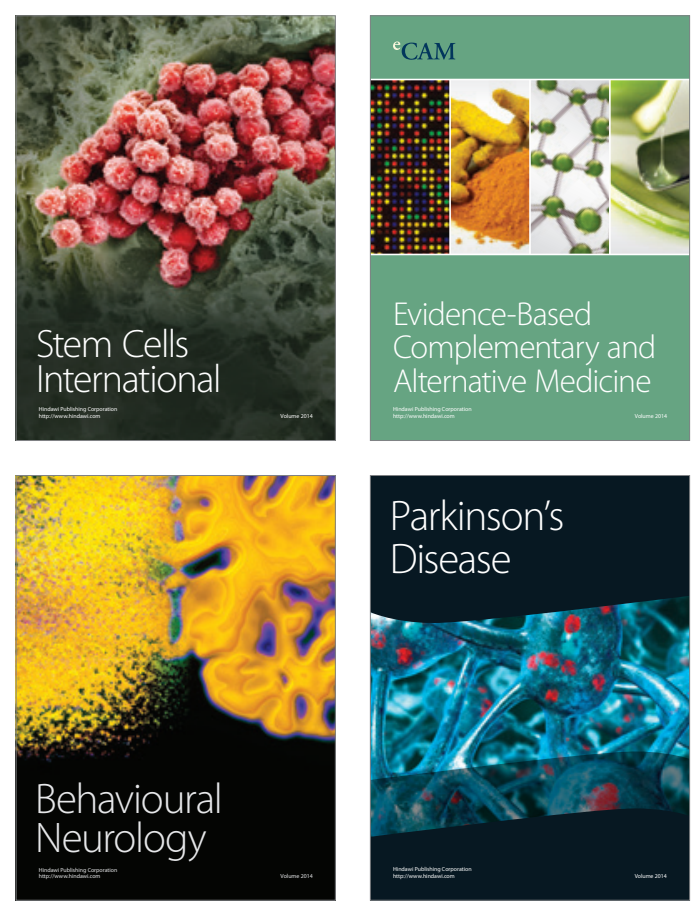

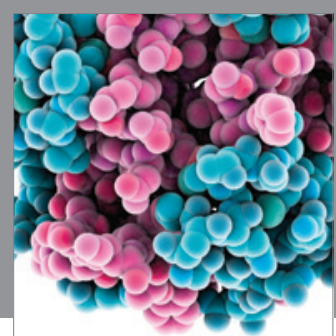

Journal of
Diabetes Research

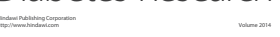

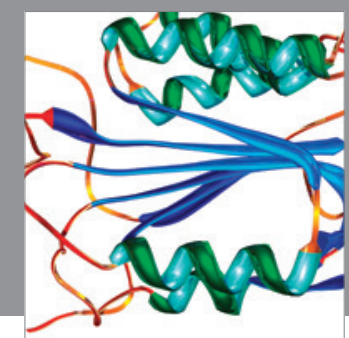

Disease Markers
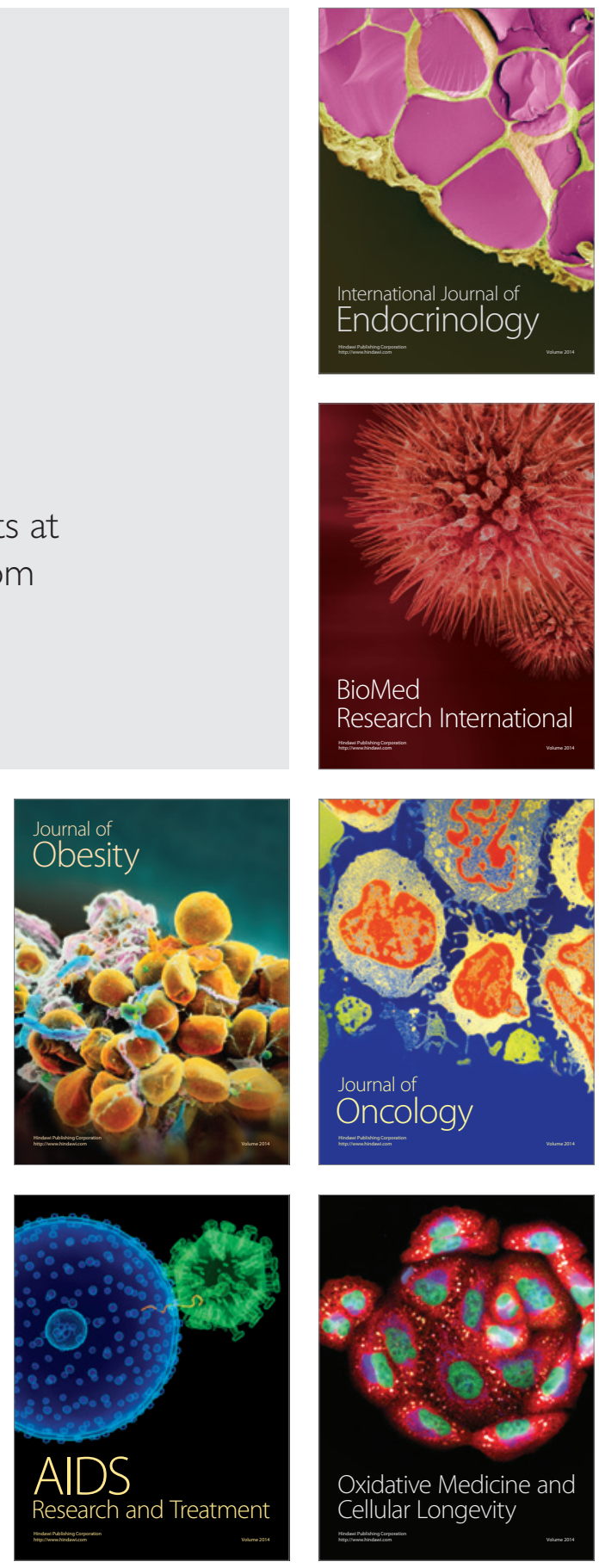